\title{
Performance Status Scale Timing Other
}

National Cancer Institute

\section{Source}

National Cancer Institute. Performance Status Scale Timing Other. NCI Thesaurus. Code C160285.

An indication that the response was other than the presented options. 